\title{
ACCELERATOR MASS SPECTROMETRY AT HIGH VOLTAGE ENGINEERING EUROPA (HVEE)
}

\author{
A Gottdang $\bullet$ M Klein $・$ D J W Mous \\ High Voltage Engineering Europa B.V., Amersfoort, the Netherlands. Email: info@ highvolteng.com.
}

\begin{abstract}
In recent years, High Voltage Engineering Europa (HVEE) has demonstrated its capability of developing and installing turnkey accelerator mass spectrometry (AMS) equipment for the analysis of, among others, ${ }^{14} \mathrm{C}$ and ${ }^{129}$ I. Five $3 \mathrm{MV}$ systems using sequential and/or simultaneous injection are operational in the field today, and they have shown excellent longterm stability providing high-precision analyses on a routine basis. Another three AMS systems are in production. It is projected that for the time being, AMS will continue to broaden its field of applications; a saturation of the market of AMS facilities is not expected in the near future.
\end{abstract}

To meet the specific demands of the biomedical research community, we have developed an extreme compact ${ }^{14} \mathrm{C}$ AMS system comprising a hybrid ion source capable of handling both graphite as well as $\mathrm{CO}_{2}$ samples. The source is optimized for easy maintenance, accommodates up to 200 samples, and can be implemented in any other AMS system.

More recently, HVEE has initiated the development of an AMS system capable of detecting, among others, ${ }^{36} \mathrm{Cl}$ and ${ }^{41} \mathrm{Ca}$. The design will include a HVEE 5MV Tandetron ${ }^{\mathrm{TM}}$. The accelerator is currently under construction as part of an ion beam analysis system for the Universidad Autonoma de Madrid (Spain).

\section{INTRODUCTION}

Since its first accelerator mass spectrometry (AMS) installation in 1993 (Gottdang et al. 1995), High Voltage Engineering Europa (HVEE) has played a major role in developing and installing turn-key AMS systems for high precision radiocarbon measurements as well as for the analysis of other longlived radioisotopes like ${ }^{129} \mathrm{I}$. Up until now, there were four dedicated ${ }^{14} \mathrm{C}$-AMS machines operating in Groningen (Netherlands), Kiel (Germany), Nagoya (Japan), and Seoul (South Korea). All these systems operate at terminal voltages of $2.5 \mathrm{MV}$ and apply a so-called recombinator for simultaneous injection of the three carbon isotopes. Detailed information on layout, characteristics, and performance can be found elsewhere (Purser 1992; Gottdang et al. 1995; Nadeau et al. 1998a). In addition, the first multi-element AMS systems has been successfully installed and accepted in Mutsu (Japan). This machine combines the layout of the ${ }^{14} \mathrm{C}$-AMS system mentioned above with an additional sequential injection system and an additional high energy beam-line for heavy radioisotopes (Gottdang and Mous 1997; Gottdang and Mous 1998). Another three dedicated ${ }^{14} \mathrm{C}-\mathrm{AMS}$ systems for Lecce (Italy), Oxford (UK), and Jena (Germany) are currently being installed or under construction. The system for Lecce is equipped with a sequential injector and the other two systems with two simultaneous injectors and two ion sources each. All these eight systems are based on a 3 MV Tandetron $^{\mathrm{TM}}$ accelerator featuring an all-solid state power supply.

An ongoing AMS project at HVEE is the development of an extreme compact ${ }^{14} \mathrm{C}$ isotope ratio mass spectrometer for biomedical applications (Mous et al. 1997). This system operates at a terminal voltage of $750 \mathrm{kV}$ and is equipped with the SO-110 hybrid negative ion sputter source capable of handling both solid graphite as well as $\mathrm{CO}_{2}$ samples. The ion source accommodates 50 or 200 samples and has been optimized for easy maintenance, low memory in the case of $\mathrm{CO}_{2}$ samples and fast sample transfer. It will be also used in the ${ }^{14} \mathrm{C}$-AMS systems for Oxford and Jena.

Another recent project at HVEE is a Tandetron ${ }^{\mathrm{TM}}$ accelerator with a terminal voltage of $5 \mathrm{MV}$. Such a system is under construction for the Universidad Autonoma de Madrid (Spain) and its main field of application will be ion beam analysis. The system will serve as a basis for a 5 MV AMS system capable of detecting, among others, ${ }^{36} \mathrm{Cl}$ and ${ }^{41} \mathrm{Ca}$.

(C) 2001 by the Arizona Board of Regents on behalf of the University of Arizona

Radiocarbon, Vol 43, Nr 2A, 2001, p 149-156

Proceedings of the 17 th International ${ }^{14} \mathrm{C}$ Conference, edited by I Carmi and E Boaretto 
Here, we will review the characteristics and performance of the ${ }^{14} \mathrm{C}-\mathrm{AMS}$ systems from HVEE. Furthermore, recent developments on the biomedical system with its hybrid ion source, as well as a new 5 MV AMS system, will be described.

\section{PERFORMANCE OF EXISTING 3 MV ${ }^{14} \mathrm{C}$-AMS SYSTEMS}

All five ${ }^{14} \mathrm{C}$-AMS systems operational in the field today apply simultaneous injection of the three carbon isotopes. Simultaneous injection offers clear advantages over sequential injection, if one aims for the highest precision (Purser 1992). On the other hand, background reduction with such systems is more complex, because during the detection of ${ }^{14} \mathrm{C}$ particles all isotopes are transported through the accelerator, thereby increasing the probability that ambiguities mimic bona fide ${ }^{14} \mathrm{C}$ events in the detector. To overcome such problems these systems have five filters in the high-energy section:

1. A high energy tube with a special, patented, inclined field electrode arrangement that is optimized to create a electrostatic dispersion, which suppresses the influence of unwanted charge exchange processes, e.g. the ${ }^{13} \mathrm{C}^{4+}$ exchanges to the ${ }^{13} \mathrm{C}^{3+}$ in the first part of the high energy tube having then the same magnetic rigidity as the ${ }^{14} \mathrm{C}^{3+}$ (Purser 1992).

2. A $110^{\circ}$ magnet for the separation of the three isotopes.

3. A $33^{\circ}$ electrostatic deflector.

4. A $90^{\circ}$ magnet.

5. An ionization chamber for the detection of the ${ }^{14} \mathrm{C}$ particles that uses both $\mathrm{dE} / \mathrm{dx}$ as well as $\mathrm{E}_{\text {final }}$.

With this setup a background level of $3.6 \times 10^{-16}$ (or $65 \mathrm{ka}$ ) and below has been achieved (Schleicher et al. 1998). This is at least comparable to other AMS machines based on sequential injection. Probably, the background of the five facilities mentioned in the introduction is entirely determined by the sample preparation.

An AMS machine for high-precision measurements demands an open ion optical architecture in order to avoid transmission losses of one or more isotopes, resulting in fractionation. This situation gets even more difficult, if the three isotopes are not exactly on one track through the machine. Certainly the narrow stripper canal requires special emphasis for optimal transmission of all three isotopes. The ion optical alignment of all three beams on one axis after the injector is therefore important. Every simultaneous injector has been individually optimized during installation for this recombination using a method based on a laser alignment (see Mous and Gottdang 1994). AMS systems from HVEE apply a stripper canal with an inner diameter of $13 \mathrm{~mm}$ and large, $330 \mathrm{~mm}$ diameter accelerator tubes in order to maintain a low vacuum level in the acceleration section.

The success of the open ion optical architecture is demonstrated in the wide flat-top tuned area present for all system parameters. As an example Figure 1 shows the ${ }^{13} \mathrm{C} /{ }^{12} \mathrm{C}$ scan of the horizontal steerer in front of the accelerator. The flat-top tuned area of about $2 \mathrm{~mm}$ in Figure 1, where the change in the ratio is far less then $0.1 \%$, can be converted to $6 \mathrm{~mm}$ at the center of the gas stripper. This implies that the beam is about a factor of 2 smaller than the inner diameter of the stripper canal. The result also indicates that an optimal recombination of the isotopes is achieved.

Long-term stability of the entire mass spectrometer is another condition for high precision ${ }^{14} \mathrm{C} /{ }^{12} \mathrm{C}$ and ${ }^{13} \mathrm{C} /{ }^{12} \mathrm{C}$ ratio measurements. To achieve this, the injector and the high energy beam-lines are designed to be achromatic, which means that small variations in beam energy do not influence the positions of the beams at the images of the injector and the ${ }^{14} \mathrm{C}$-detector. In addition to this a slit 


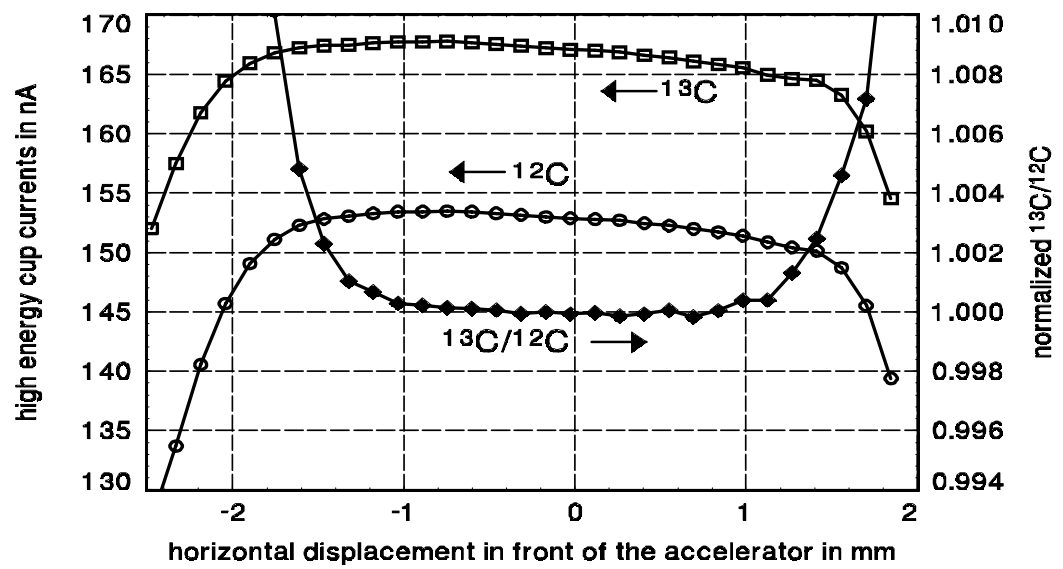

Figure 1 Horizontal steerer scan of ${ }^{13} \mathrm{C}$ and ${ }^{12} \mathrm{C}$ currents measured in the high energy Faraday cups of the $3 \mathrm{MV}{ }^{14} \mathrm{C}$-AMS machine

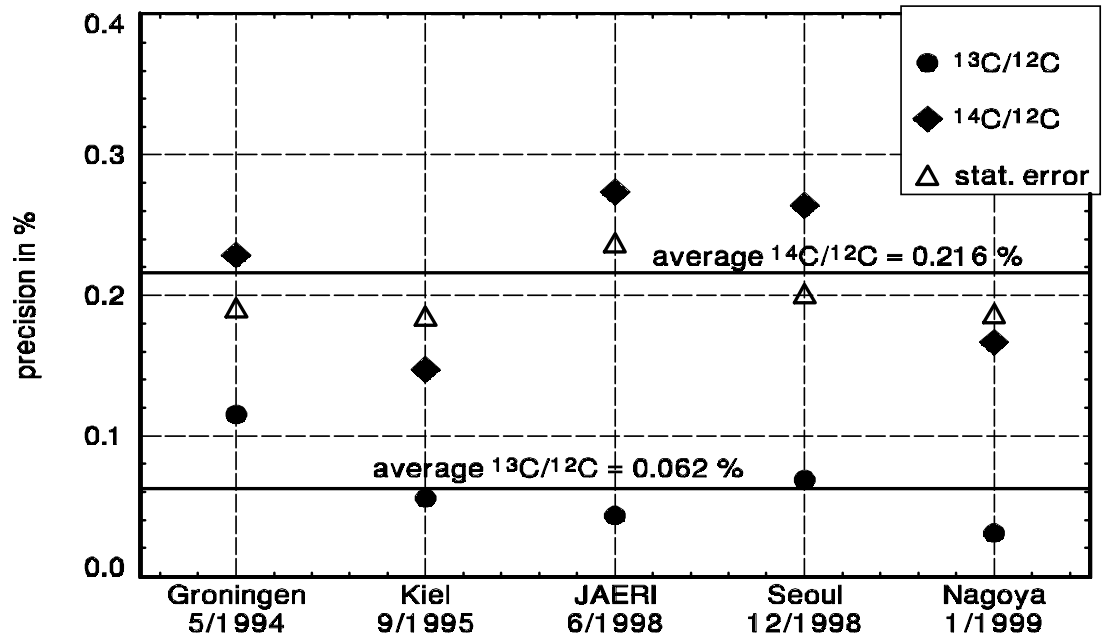

Figure 2 Results from the acceptance tests of the five HVEE ${ }^{14} \mathrm{C}$-AMS systems. The data show the average precision from two succeeding days for ${ }^{14} \mathrm{C} /{ }^{12} \mathrm{C}$ and ${ }^{13} \mathrm{C} /{ }^{12} \mathrm{C}$, as well as the averaged uncertainty from the counting statistics. Six modern samples were measured on each day.

feedback system, located in the high energy ${ }^{13} \mathrm{C}$ Faraday cup, guarantees a stable position of the trajectories of all three isotopes in the high energy section.

Figure 2 shows the results from the acceptance tests of all HVEE ${ }^{14} \mathrm{C}$-AMS systems operational today. The data points represent the averages of uncertainties of the ${ }^{14} \mathrm{C} /{ }^{12} \mathrm{C}$ and ${ }^{13} \mathrm{C} /{ }^{12} \mathrm{C}$ ratios obtained on two succeeding days. The overall average precision is $0.06 \%$ for ${ }^{13} \mathrm{C} /{ }^{12} \mathrm{C}$ and $0.216 \%$ for ${ }^{14} \mathrm{C} /{ }^{12} \mathrm{C}$ with a statistical uncertainty of $0.20 \%$. Taken the influence of counting statistics into account, the numbers on the precision of ${ }^{14} \mathrm{C} /{ }^{12} \mathrm{C}$ show a machine contribution of $0.08 \%$, which is close to the ${ }^{13} \mathrm{C} /{ }^{12} \mathrm{C}$ uncertainty. This is confirmed by data taken during routine operation. From 
1164 samples (background and unknowns) measured during nine months, Nadeau et al. (1998b) have found that the most probable uncertainty for ${ }^{13} \mathrm{C} /{ }^{12} \mathrm{C}$ is at $0.013 \%$.

The tuning of the system is straightforward and supported by strong diagnostic tools resulting in reproducible machine settings for all system parameters. Nadeau et al. (1998a) have reported that variations in the settings of the dispersive components are in the order of $10^{-3}$ over month.

\section{STATUS OF THE COMPACT ${ }^{14} \mathrm{C}$-AMS SYSTEM FOR BIOMEDICAL APPLICATIONS}

The recent past has shown a trend in increasing use of AMS for biomedical applications (Mous et al. 1997), but the real breakthrough for AMS in biomedical research will strongly depend on the acceptance of AMS by the biomedical community. The availability of small and easy to operate machines, which fit easily in normal laboratory environments and which do not require specially trained accelerator personnel, can significantly facilitate the acceptance of this analytical tool in the field of biomedical research. Furthermore, it would be advantageous if the system could be coupled directly to a GC or CHN analyzer for online analyses.

HVEE has started the development of such an ${ }^{14} \mathrm{C}$ isotope mass spectrometer for biomedical applications with the aim of creating an extremely compact machine having a precision of about $2 \%$ and a ${ }^{14} \mathrm{C} /{ }^{12} \mathrm{C}$ background of $10^{-13}$, easy and reliable system operation, highly automated, high sample throughput and the possibility to feed the system with $\mathrm{CO}_{2}$ samples from ground potential. The outcome is a system based on a $750 \mathrm{kV}$ folded tandem accelerator with a foil stripper and a footprint of $2.25 \mathrm{~m} \times 1.2 \mathrm{~m}$. The major components of the system are:

- Negative ion sputter source SO-110.

- Injector with an $90^{\circ}$ analyzing permanent magnet, the ${ }^{12} \mathrm{C}$ - Faraday cup and a $90^{\circ}$ electrostatic analyzer.

- Low-energy accelerator tube.

- Terminal with stripper foil and $180^{\circ}$ electrostatic analyzer.

- High-energy accelerator tube.

- Gridded lens and $23^{\circ}$ analyzing magnet.

- Ionization chamber for the detection of the ${ }^{14} \mathrm{C}$ particles.

Mous et al. (1997) have given a detailed layout and a system description. The source was developed in collaboration with the AMS group of Oxford (Mous et al. 1998). Figure 3 shows the schematic layout of the SO-110 and its characteristics are reflected in the following features:

- Acceptance of both graphite as well as $\mathrm{CO}_{2}$ samples admitted from ground potential.

- Stainless steel source body on ground potential, which ensures easy and safe operation.

- Easy exchangeable sample carousel with 50 or 200 sample storage capacity and fast carousel exchange times. Pump down times are about 5 min before the next analysis can be started.

- Fast sample transfer within $7 \mathrm{sec}$ for neighboring samples.

- Easy maintenance by sideways extraction of the source head (see Figure 3) without the need of realignment after reinserting.

- Excellent pumping due to a $360 \mathrm{~L} / \mathrm{sec}$ turbine pump located close to the source head ensures low background for $\mathrm{CO}_{2}$ samples. The sample-to-sample memory effect when using $\mathrm{CO}_{2}$ is at or below $10^{-3}$, which is sufficient for most biomedical applications (Mous et al. 1999).

- Up to $270 \mu \mathrm{A}$ analyzed ${ }^{12} \mathrm{C}^{-}$current from solid graphite samples and up to $12 \mu \mathrm{A}$ analyzed ${ }^{12} \mathrm{C}^{-}$ current from $\mathrm{CO}_{2}$ samples. 


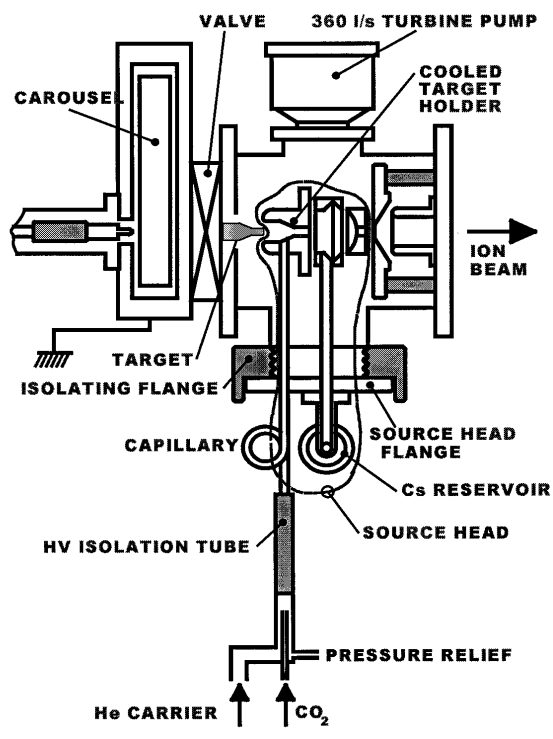

Figure 3 Schematic layout of the negative ion source SO110 for solid as well as and $\mathrm{CO}_{2}$ samples

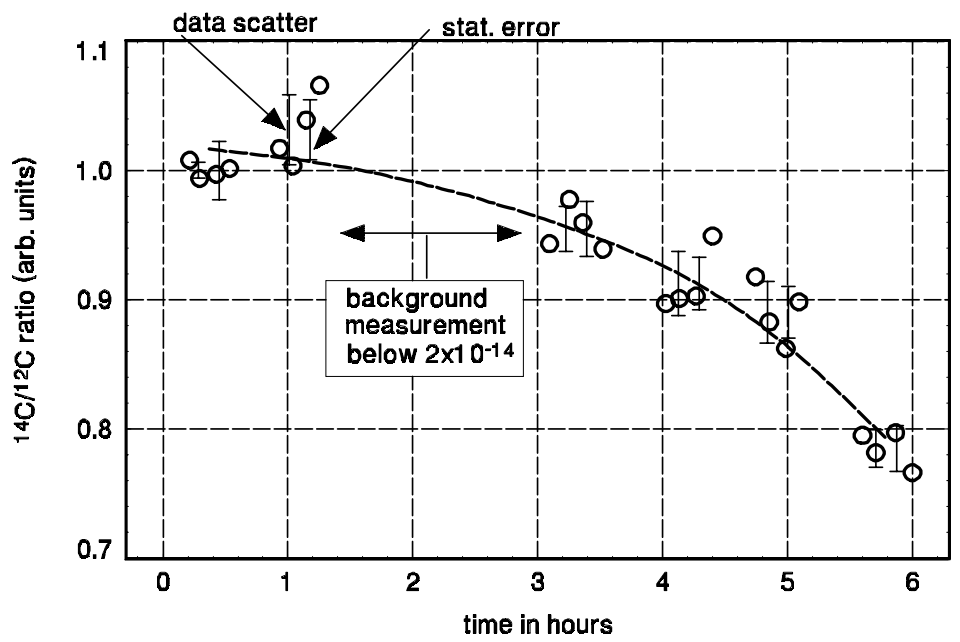

Figure $4{ }^{14} \mathrm{C} /{ }^{12} \mathrm{C}$ precision measurements with the biomedical ${ }^{14} \mathrm{C}$ IRMS. Four samples have been used in six runs. Between runs 2 and 3, a background sample (commercial graphite) has been measured. The dashed line is a weighed spline fit through the averages of each run and is meant to guide the eye.

Mous et al. (1999) have shown, that the ion optical performance of the system has reliable flat-top tuning and that the ${ }^{14} \mathrm{C} /{ }^{12} \mathrm{C}$ background is below $10^{-13}$. These results were obtained with the charge state $2+$ selected in the high-energy section. This charge state has been found to be troublesome, because of the interfering ${ }^{7} \mathrm{Li}$-dimer, which cannot be resolved from the ${ }^{14} \mathrm{C}$ particles by means of electrostatic or magnetic filters (Mous et al. 1999). The ${ }^{7} \mathrm{Li}$ particles, probably originating from the $\mathrm{Cs}$ in the ion source, appear in the detector occasionally in form of bursts. These bursts can adversely influence precision. For this reason, modifications in the system were employed in order to test the system using the charge state $3+$. 
Figure 4 shows results for ${ }^{14} \mathrm{C} /{ }^{12} \mathrm{C}$ precision with this new setup. Four modern graphite samples have been repeatedly analyzed over a period of $6 \mathrm{hr}$. After the second run a sample, made from commercial graphite powder, has been analyzed in order to determine the background level. A level of less than 2 $\times 10^{-14}$ for the ${ }^{14} \mathrm{C} /{ }^{12} \mathrm{C}$ ratio has been obtained, while the same sample material was analyzed to have ${ }^{2}{ }^{14} \mathrm{C} /{ }^{12} \mathrm{C}$ ratio of $1.3 \times 10^{-14}$ with the high precision ${ }^{14} \mathrm{C}$-AMS system in Groningen. This indicates that the background contribution of the machine is below $10^{-14}$. The ${ }^{14} \mathrm{C} /{ }^{12} \mathrm{C}$ precision in each run is better then $2 \%$ and dominated by the statistical uncertainty. A clear decrease of the absolute ${ }^{14} \mathrm{C} /{ }^{12} \mathrm{C}$ ratio with time is visible, which results from a decreasing transmission of the ${ }^{14} \mathrm{C}$ particles to the detector. This change in transmission is resulting from a change in the stripper foil thickness, which changes the absolute energy loss of the ${ }^{14} \mathrm{C}$ particles in the foil. The setting of the electrostatic $180^{\circ}$ deflector, which is located after the foil stripper in the terminal, no longer corresponds with the changed particle energy. This can be seen in Figure 5, in which a scan of the $180^{\circ}$ deflector before and after a foil exposure of a few hours is shown. The shift in particle energy of $3.1 \mathrm{keV}$ between both curves can be converted to an increase in foil thickness from $2.7 \mu \mathrm{g} / \mathrm{cm}^{2}$ to $3.4 \mu \mathrm{g} / \mathrm{cm}^{2}(+25 \%)$. This energy variation demands a new tuning of the $180^{\circ}$ deflector every few hours, but tests have shown, that the original absolute ${ }^{14} \mathrm{C} /{ }^{12} \mathrm{C}$ ratio cannot be established anymore. This is due to the increased small angle scattering in the stripper foil. The resulting increase in the phase space is too big for the acceptance of the following ion optical system and transmission losses of the ${ }^{14} \mathrm{C}$ particles occur. Possible solutions for this last remaining problem are currently under investigation.

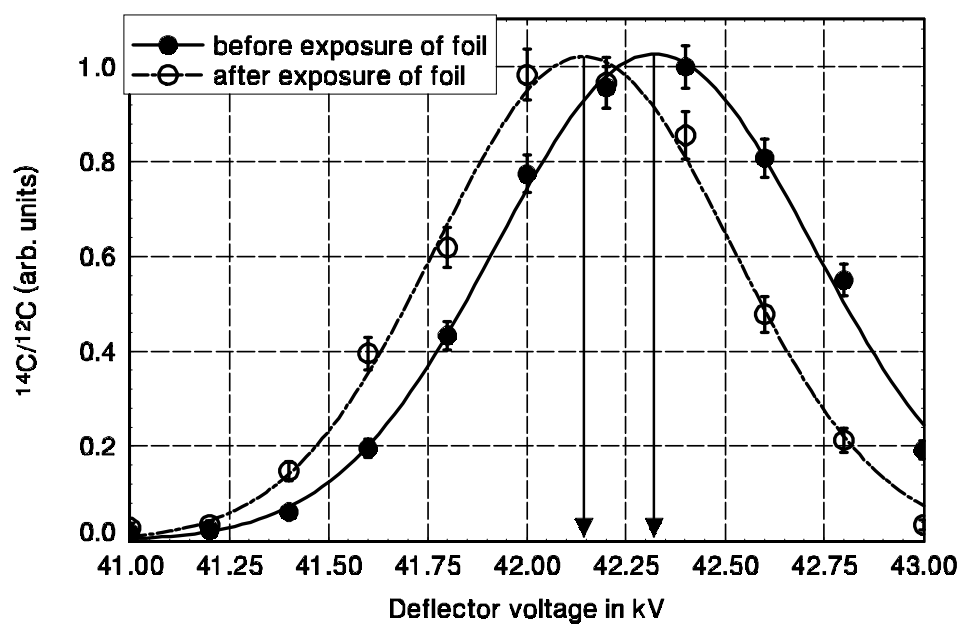

Figure 5 Scans with the $180^{\circ}$ deflector (located in the terminal of the accelerator) taken before and after a few hours of foil exposure. The solid and dashed lines are representing gaussian fits. The terminal voltage was set to $750 \mathrm{kV}$ and the resulting shift in particle energy between both measurements is calculated to be $3.1 \mathrm{keV}$.

\section{THE NEW 5 MV TANDETRONTM FOR AMS APPLICATIONS}

More recently, HVEE has initiated the development of an AMS system capable to detect, among others, ${ }^{36} \mathrm{Cl}$ and ${ }^{41} \mathrm{Ca}$. The design, shown in Figure 6, will include the new HVEE 5 MV Tandetron $^{\mathrm{TM}}$. Such a $5 \mathrm{MV}$ accelerator is currently under construction as part of an ion beam analysis system for the Universidad Autonoma de Madrid (Spain.) The low energy side combines a simultaneous injector for high precision ${ }^{14} \mathrm{C}$ analysis and a sequential injector for heavy element AMS. The high-energy section consists of two magnets, a $30^{\circ}$ electrostatic deflector and a multi-anode gas ion- 
ization detector. Table 1 shows the anticipated system performance for various long-lived radioisotopes. An all-solid state power supply (parallel fed Cockroft-Walton type) is constructed around the high-energy tube and generates stable and almost maintenance free operation. Special effort during the design of the accelerator has been made in order to minimize the electrical field strength in the complete structure. With the aid of three dimensional electrostatic field mapping the maximum field strength in this accelerator has been reduced to about $80 \%$ compared to older designs. This guarantees more reliable operation at or even above the design aim of $5 \mathrm{MV}$.

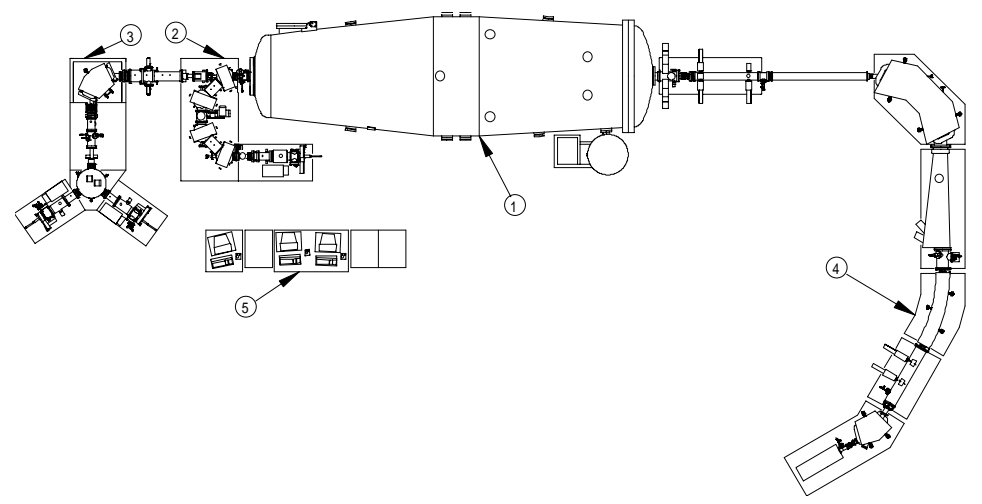

Figure 6 Layout of the new AMS system, based on a 5 MV Tandetron (1), with a simultaneous injector for high precision ${ }^{14} \mathrm{C}$-AMS (2), a sequential injection system for multi-element AMS with an optional ion source (3), the high-energy section (4) and the computer control (5).

Table 1 Anticipated system performance of the new

\begin{tabular}{ccc}
\multicolumn{3}{l}{5 MV AMS system } \\
\hline Isotope ratio & Precision in \% & Background \\
\hline${ }^{14} \mathrm{C} / /^{12} \mathrm{C}$ & 0.3 & $1 \times 10^{-15}$ \\
${ }^{13} \mathrm{C} / 12 \mathrm{C}$ & 0.1 & - \\
${ }^{10} \mathrm{Be} /{ }^{12} \mathrm{Be}$ & 3.0 & $3 \times 10^{-15}$ \\
${ }^{26} \mathrm{Al} /{ }^{27} \mathrm{Al}$ & 3.0 & $5 \times 10^{-15}$ \\
${ }^{36} \mathrm{Cl} / \mathrm{Cl}$ & 3.0 & $5 \times 10^{-15}$ \\
${ }^{41} \mathrm{Ca} /{ }^{40} \mathrm{Ca}$ & 3.0 & $5 \times 10^{-13}$ \\
${ }^{129} \mathrm{I} / 127 \mathrm{I}$ & 1.0 & $1 \times 10^{-13}$ \\
\hline
\end{tabular}

\section{CONCLUSIONS}

The acceptance tests of all five ${ }^{14} \mathrm{C}$ AMS system installed by HVEE demonstrate a typical ${ }^{13} \mathrm{C} /{ }^{12} \mathrm{C}$ precision of $0.06 \%$, which is confirmed by results of data taken on a routine basis. Taken Poisson statistics into account, precision of ${ }^{14} \mathrm{C} /{ }^{12} \mathrm{C}$ is at same level. Background of these systems is probably entirely determined by sample preparation. Such performance is made possible by an open ion optical architecture resulting in wide flat-top tuning for all system parameters. Stability for all system parameters is in the order of $10^{-3}$ over periods of months showing the excellent long-term stability of the entire AMS system.

The ${ }^{14} \mathrm{C}$-AMS system for biomedical applications is characterized by its extreme compact system design with a footprint of $2.25 \mathrm{~m} \times 1.2 \mathrm{~m}$, easy and reliable system operation, high sample through- 
put, the possibility to measure solid graphite samples as well as $\mathrm{CO}_{2}$ samples, a background level below $1 \times 10^{-14}$ and a short term precision at or below $2 \%$. At present, the long-term precision is limited due to the thickening of the carbon stripper foil.

Based on a new developed Tandetron ${ }^{\mathrm{TM}}$, 5 MV AMS systems are now available from HVEE for high precision ${ }^{14} \mathrm{C}$ analyses as well as for the detection of other long-lived radioisotopes, such as ${ }^{10} \mathrm{Be}$, ${ }^{26} \mathrm{Al},{ }^{36} \mathrm{Cl},{ }^{41} \mathrm{Ca}$ and ${ }^{129} \mathrm{I}$.

\section{REFERENCES}

Gottdang A, Mous DJW, van der Plicht J. 1995. The HVEE ${ }^{14} \mathrm{C}$ system at Groningen. In: Cook GT, Harkness DD, Miller BF, Scott EM, editors. Proceedings of the 15 th International ${ }^{14} \mathrm{C}$ Conference. Radiocarbon 37(2):649-56.

Gottdang A, Mous DJW. 1997. The novel HVEE multielement AMS system. Nuclear Instruments and Methods in Physics Research B123:163-6.

Gottdang A, Mous DJW. 1998. The Characteristics of the HVEE multi-element AMS system. Proceedings of the 15th International Conference on Applications of Accelerators in Research and Industry. Denton, Texas, USA, Nov. 1998:652-6.

Nadeau M-J, Schleicher M, Grootes PM, Erlenkeuser H, Gottdang A, Mous DJW, Sarntheim JM, Willkomm H. 1998a. The Leibniz-Labor AMS facility at the Christian-Albrechts-University, Kiel, Germany. Nuclear Instruments and Methods in Physics Research B123:2230.

Nadeau M-J, Grootes PM, Schleicher M, Hasselberg P, Rieck A, Bitterling M. 1998b. Sample throughput and data quality at the Leibniz-Labor AMS facility. Radiocarbon 40(1):239-45.

Mous DJW, Gottdang A. 1994. Status of the first HVEE
${ }^{14} \mathrm{C}$ AMS in Groningen. Nuclear Instruments and Methods in Physics Research B92:12-5.

Mous DJW, Purser KH, Fokker W, van den Broek R, Koopmans RB. 199.7 A compact ${ }^{14} \mathrm{C}$ isotope ratio mass spectrometer for biomedical applications. $\mathrm{Nu}$ clear Instruments and Methods in Physics Research B 123:159-62.

Mous DJW, Fokker W, van den Broek R, Koopmans R, Bronk Ramsey C, Hedges REM. 1998. An ion source for the $\mathrm{HVEE}{ }^{14} \mathrm{C}$ isotope ratio mass spectrometer for biomedical applications. Radiocarbon 40(1):283-8.

Mous DJW, Gottdang A, Fokker W, van den Broek R, Koopmans RB. 1999. The HVEE ${ }^{14} \mathrm{C}$ isotope ratio mass spectrometer for biomedical applications. Proceedings of the 15th International Conference on Applications of Accelerators in Research and Industry. Denton, Texas, USA, Nov. 1998:657-60.

Purser KH. 1992. A high throughput ${ }^{14} \mathrm{C}$ accelerator mass spectrometer. Radiocarbon 34(3):458-67.

Schleicher M, Grootes PM, Nadeau M-J, Schoon A. 1998. The carbonate ${ }^{14} \mathrm{C}$ background and its components at the Leibniz AMS facility. Radiocarbon 40(1): 85-93. 